\title{
Development of Evaluation Method for Damage of Oxidation CoNiCrAlY Coating
}

\author{
Mo Chen ${ }^{1,2, a}$, Kodai Yoshikawa ${ }^{1}$, Zhenqiang Song ${ }^{1, b}$ and Shijie Zhu ${ }^{1, c^{*}}$
}

${ }^{1}$ Department of Intelligent Mechanical Engineering, Graduate School of Engineering, Fukuoka Institute of Technology, Japan

${ }^{2}$ Department of Energy and Powering Engineering, Graduate School of Nanjing University of Science and Technology, China

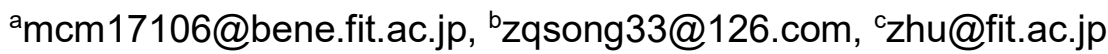

Keywords: CoNiCrAIY coating, TGO, Plasma spray, Thermal exposure, Residual stress

\begin{abstract}
The bond coat plays an important role in the failure of the thermal barrier coating (TBC) system used for gas turbines ${ }^{[1,2]}$. In this research, the CoNiCrAlY coated Ni-base superalloy specimens were used for developing evaluation method for interfacial damage in the coating system. Samples were exposed at $1000^{\circ} \mathrm{C}$ and $1100^{\circ} \mathrm{C}$ for up to 1000 hours. The morphology and residual stress in the thermally grown oxide (TGO) layer on the CoNiCrAlY coating were characterized by microscopic observation and luminescence spectroscope, respectively. The microstructure and damage on both the coating surfaces and the cross sections were observed by optical microscope and scanning electron microscope. According to the results, the low pressure plasma sprayed CoNiCrAlY coating (LPPS) showed the thinnest TGO layer and lowest residual stress. Residual stress decreased with an increase in exposure time, depending on the morphology of TGO layer. The effects of thermal spraying methods on the oxidation of yttrium in TGO layer and BC layer and its influence on interfacial damage were discussed.
\end{abstract}

\section{Introduction}

Increasing the inlet temperature of gas turbines is the main way to increase their efficiency. This requires to increase the heat resistance of materials used for gas turbines. The thermal barrier coatings (TBCs) on high temperature alloys can increase the heat resistance for $100-300^{\circ} \mathrm{C}$. In the $\mathrm{TBC}$ system, there are two main parts: the top coat (TC) and the bond coat (BC). The metallic BC, usually MCrAlY, where $\mathrm{M}=\mathrm{Ni}$ and/or $\mathrm{Co}$, is an important component of TBC system. It enhances the adhesion of TC to the substrate and also provides oxidation and corrosion protection to the substrate metal ${ }^{[3]}$. At high temperature, however, the thermally grown oxide (TGO) appears between the TC and the BC. With the TGO growing, damage between the TGO and the $\mathrm{BC}$ results in failure of the TBC system.

In this study, the specimens made by different spraying methods were exposed at $1000^{\circ} \mathrm{C}$ and $1100^{\circ} \mathrm{C}$ for up to 1000 hours. We investigated the morphology and the residual stresses of the specimens after thermal exposure to verify the relationship between the oxidation behavior of the TGO and the interfacial damage of the TBC. Elemental distribution was measured by EDS to show the influence on the damage.

\section{Experimental}

The samples were schematically showed in Figure 1. CoNiCrAlY coatings were sprayed onto the subtrates of Inconel 738LC, by three different spraying methods: the atmospheric plasma spraying (APS), the low pressure plasma spraying (LPPS) and the high velocity oxygen fuel (HVOF). The thickness of the $\mathrm{BC}$ was about $150 \mu \mathrm{m}$. 


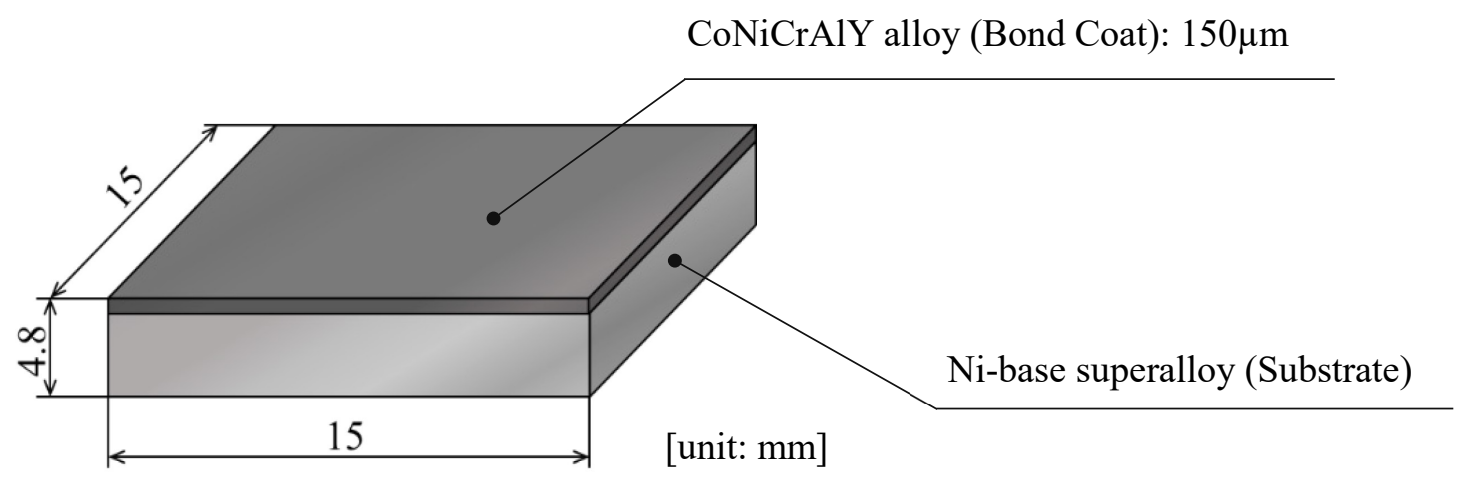

Figure 1. Schematic diagram showing CoNiCrAlY coating specimen

All the specimens were divided into several groups and were exposed in the electric furnace respectively under the conditions shown in Table 1.

Table 1 Conditions of thermal exposure

\begin{tabular}{|c|c|c|}
\hline $\begin{array}{c}\text { Thermal exposure } \\
\text { temperature }\end{array}$ & $\begin{array}{c}\text { Spraying } \\
\text { method }\end{array}$ & $\begin{array}{c}\text { Thermal } \\
\text { exposure time }\end{array}$ \\
\hline \multirow{2}{*}{$1000^{\circ} \mathrm{C}$} & APS & \multirow{2}{*}{$10 \mathrm{~h}, 100 \mathrm{~h}, 300 \mathrm{~h}}$, \\
$1100^{\circ} \mathrm{C}$ & LPPS & $600 \mathrm{~h}, 1000 \mathrm{~h}$ \\
\cline { 2 - 2 } & HVOF & \\
\hline
\end{tabular}

All the specimens were observed by the optical microscope and the field emission scanning electron microscope (FE-SEM). Elemental distribution was measured by Energy Dispersive Spectroscopy (EDS).

Fluorescence spectrum was used to evaluate the residual stress in the TGO. The observed piezospectroscopic shifts were attributed to residual stresses in the thermally grown oxide. When alumina was stressed, the wave number of the $\mathrm{R}$ lines shifted from their stress-free values. The peak shift $(\Delta v)$ was measured for calculating the TGO's residual stress $(\sigma)$ by the following expression:

$$
\sigma=\frac{3 \Delta v}{2 \Pi}
$$

where $\Pi$ (piezospectroscopic coefficient) was $7.61 \mathrm{~cm}^{-1} / \mathrm{GPa}^{[4]}$.

\section{Results and Discussion}

TGO formed on the bond coat after thermal exposure. Figure 2 is microscopic images on cross section of the specimens showing the TGO of the APS coating.

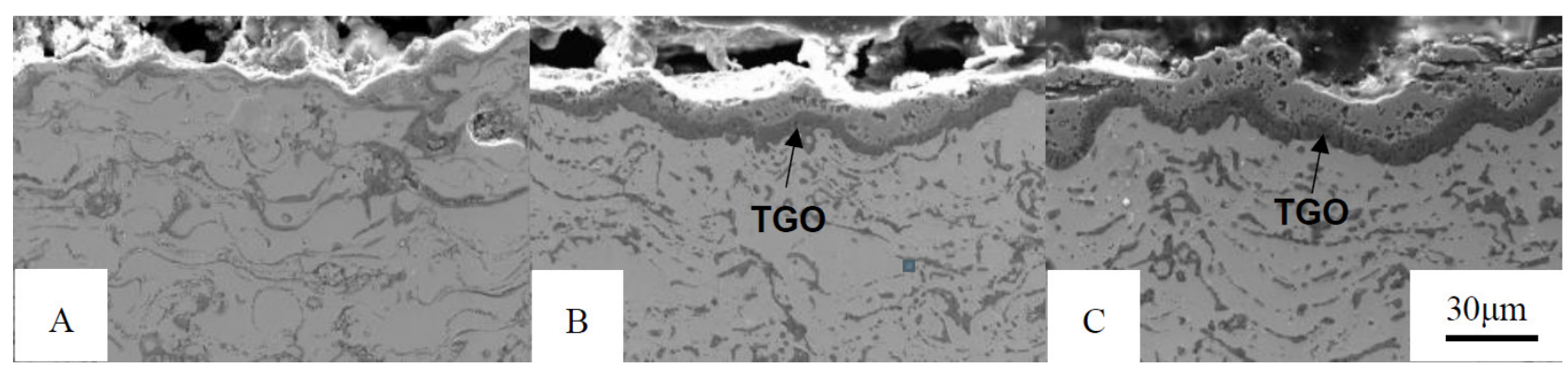

Figure 2. Cross-sectional view of APS coating exposed at $1100^{\circ} \mathrm{C}$ 
It can be found that, with an increase in exposure time, the thickness of TGO increases. After 10 hours exposure, a thin TGO layer can be seen on the bond coat. The layer of TGO (black and grey color) formed on the bond coat after 300 hours exposure. Both the two TGO layers became thicker after 1000 hours exposure. The other two types of bond coatings have the similar process during the heat treatment.
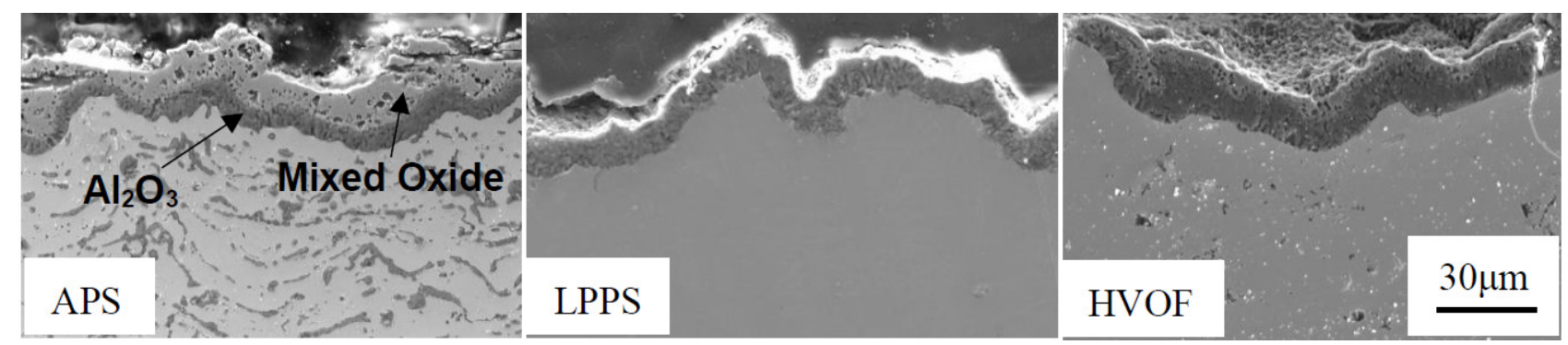

Figure 3. Comparison of three kinds of specimens after thermal exposure at $1100^{\circ} \mathrm{C}$ for $1000 \mathrm{~h}$

Figure 3 shows SEM images of three kinds of specimens after thermal exposure at $1100^{\circ} \mathrm{C}$ for 1000h. LPPS coating shows the thinnest TGO layer and almost has no mixed oxide above the alumina layer while the other two types of specimens have obvious dividing line between the alumina layer and the mixed oxide layer.

Relationship of residual stress with thickness of TGO layer exposed at $1100^{\circ} \mathrm{C}$ is shown in Figure 4. In this figure, the residual stress decreases with the TGO growing. The order of the residual stress is $\mathrm{APS}>\mathrm{HVOF}>\mathrm{LPPS}$.

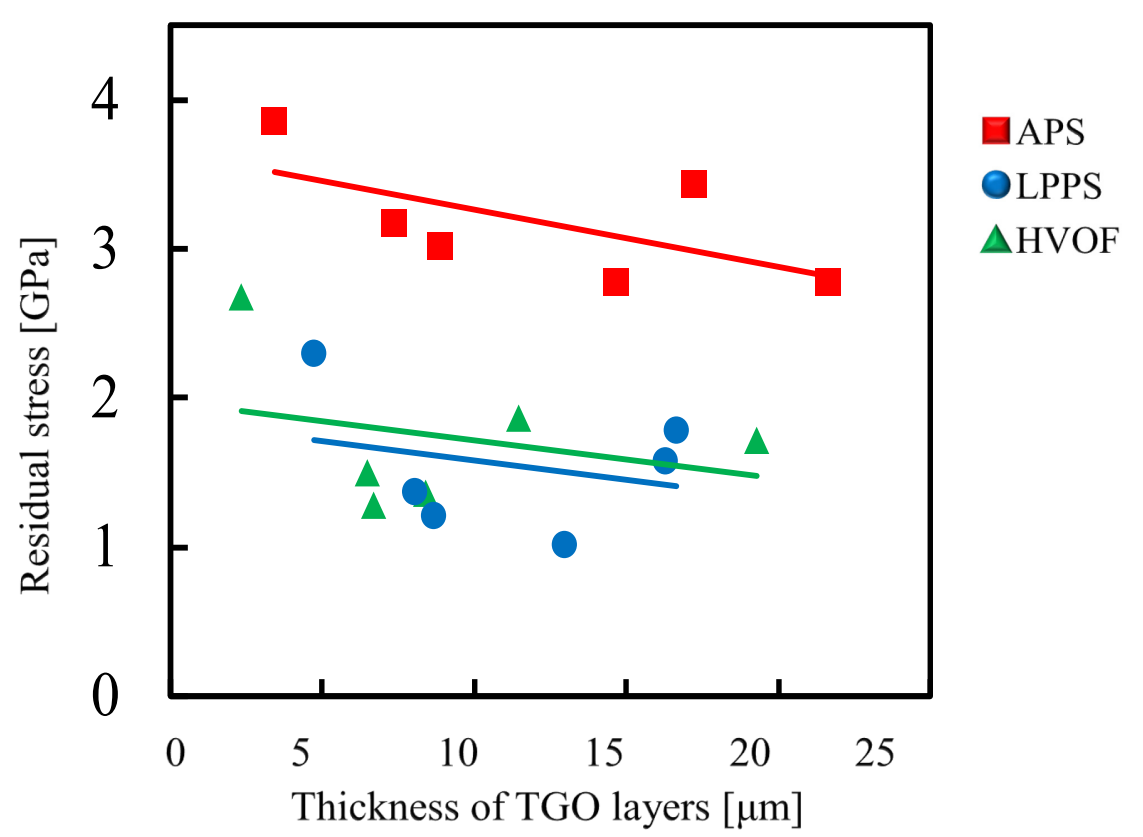

Figure 4. Relationship of residual stress with thickness of TGO layer exposed at $1100^{\circ} \mathrm{C}$ 
Figure 5 shows the elemental distributions, especially the distributions of Y (pink), Cr (yellow) and Al (blue) in the TGO layers of HVOF and LPPS specimens. It is obvious that the TGO layers mainly consist of the element Al. However, above the alumina layer, the mixed oxide layer in Figure 5(a) is much thicker than that in Figure 5(b). Besides, the element $Y$ can hardly be found in Figure 5(a) while the almost vertical distribution of Y can be seen obviously in the TGO layer of LPPS specimen。

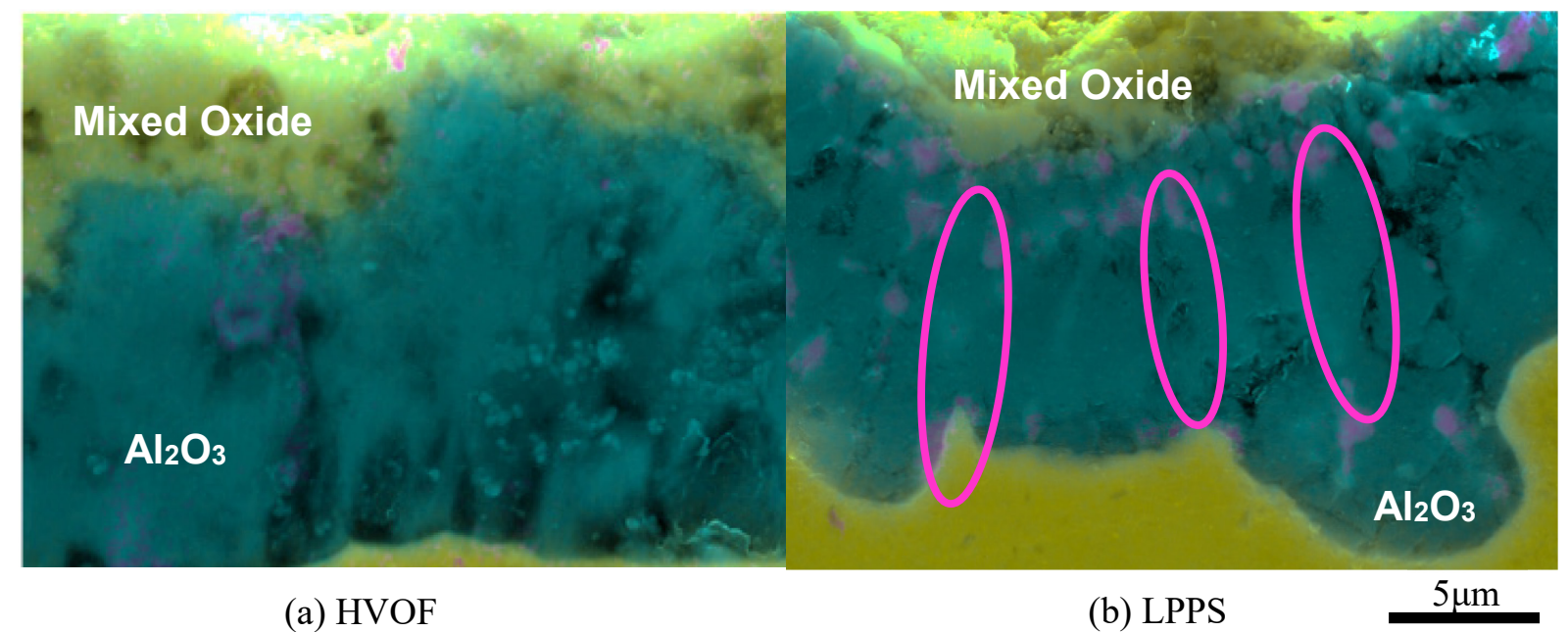

Figure 5. Elemental analysis of specimens after thermal exposure at $1100^{\circ} \mathrm{C}$ for $1000 \mathrm{~h}$

According to previous research, when the active element is close to the coating/layer interface, at a very high temperature, it would diffuse along the grain boundary ${ }^{[5]}$. During this process, it precipitates as active element-enriched oxide in the middle or on the surface of the layer. The active element is dissolved in the oxide layer to improve the plastic deformability and adhesion strength and relax the thermal stress ${ }^{[5]}$. According to Jedliski's research ${ }^{[6]}$, active element Y can form precipitate phase $\mathrm{Ni}_{5} \mathrm{Y}$ along the grain boundary which can be oxidized to form $\mathrm{Y}_{2} \mathrm{O}_{3}$. Active element-enriched oxide can inhibit the grain growth of unstable alumina and increase the vacancy concentration of the unstable alumina. Therefore, active element can accelerate the phase transformation of unstable alumina into $\alpha-\mathrm{Al}_{2} \mathrm{O}_{3}$. The $\alpha-\mathrm{Al}_{2} \mathrm{O}_{3}$ is stable and can form compact oxide film which can protect the bond coat. It is obvious that alumina layer in HVOF specimen is not as dense as that in LPPS specimen, probably because the unstable alumina in HOVF specimen is more than that in LPPS specimen.

\section{Conclusion}

After thermal exposure, the LPPS specimen showed the thinnest TGO layer. The residual stress tended to decrease with an increase in thermal exposure time. The order of the residual stress was APS $>$ HVOF $>$ LPPS. The active element (such as Y) distribution in the TGO layers was quite different. The distribution of active element might influence the oxidation behavior of the layer. 


\section{References}

[1]R. Vaßen, et al. Overview on advanced thermal barrier coatings, Surface \& Coatings Technology, 2010 (205), pp. 938-942.

[2]M. Shibata, et al. Comparison of microstructure and oxidation behavior of CoNiCrAlY bond coatings prepared by different thermal spray processes, Materials Transactions, 2006 (47), pp. 6381642 .

[3]W.R. Chen, et al. TGO growth behavior in TBCs with APS and HVOF bond coats, Surface \& Coatings Technology, 2008 (202), pp. 2677-2683.

[4]J.A. Nychka, D.R. Clarke. Damage quantification in TBCs by photo-stimulated luminescence spectroscopy. Surface \& Coatings Technology. 2001 (146-147), pp. 110-116.

[5]K. Yoshikawa. Microscopic analysis and residual stress evaluation of high temperature oxide on CoNiCrAlY coating, Master's thesis, Fukuoka Institute of Technology, 2017.

[6]J. Jedliski. Comments on the effect of yttrium on the early stages of oxidation of alumina formers, Oxidation of Metals, 1993 (39), pp. 55-60. 